\title{
КРУПНОПЛОДНОСТЬ У ТОМАТА Solanum lycopersicum L.: ГЕНЕТИЧЕСКИЕ ДЕТЕРМИНАНТЫ, ОРГАНОГЕНЕЗ И РАЗВИТИЕ ПЛОДА

\author{
(обзор)
}

\author{
И.Т. БАЛАШОВА ${ }^{凶}$, С.М. СИРОТА, Е.В. ПИНЧУК
}

Крупноплодность у Solanum lycopersicum L. возникла в результате доместикации. Способность растений томата формировать крупный плод вызывает интерес в связи с созданием образцов для многоярусных гидропонных и аэропонных установок, применение которых - основной тренд современного вертикального овощеводства в защищенном грунте. Используя технологию целевой селекции, мы получили первые российские мелкоплодные сорта томата для многоярусной узкостеллажной гидропоники - Наташа и Тимоша. Укрупнение плода связано с генетическими и эпигенетическими механизмами контроля этого признака, которые активно изучаются у томата как модельного объекта (An. Frary с соавт., 2000; B. Cong с соавт., 2006; Z. Huang с соавт., 2011; S. Wang, с соавт., 2011; A.J. Monforte с соавт., 2014; L. Azzi с соавт., 2015). В своем обзоре мы сконцентрировали внимание на данных о генах, участвующие в контроле массы плода у томата, и возможностях регулировать их экспрессию, которые, по нашему мнению, представляют первоочередной интерес для селекции. Цель обзора - обобщение сведений о генетических детерминантах массы плода у томата и их связи с органогенезом, гормональной и метаболической регуляцией развития плода. Анализ научных публикаций, затрагивающих тему укрупнения плода у томата при доместикации, выявил наличие 37 локусов, регулируюших деление и расширение клеток на четырех этапах развития плода от фазы развития яйцеклетки и фазы формирования завязи после оплодотворения до фазы клеточного деления и фазы расширения клеток, формирующих зрелый плод. Часть этих локусов связаны с процессами гормонального развития растения в фазы цветения, оплодотворения, образования плодов и семян и поэтому вовлечены в ауксиновый (SIPIN4, SITIR1, SlARF7, SlARF8, SIIAA9) и гиббереллиновый (SlGA20ox1, SIDELLA1) сигналинги. Другие локусы контролируют расширение клеток в период развития и созревания плода, и поэтому вовлечены в процессы регуляции первичного (HXK1, SuSY, LIN5, TIV1, mMDH, cpFBP, SPA) и вторичного (NOTABILIS/NCED1, FLACCA, Gal-LDH, GME) метаболизма. Отдельная группа локусов контролирует клеточный цикл в период развития яйцеклетки (TAGL1, FAS, LC, SIWUS, SIIMA) и увеличения плода (SICDKA1, SICDCB1, SICDKB2 и SlCCS52A, SlWEE1, SlKRP1) (L. Azzi с coaвT., 2015). Из локусов, определяющих размер плода у томата, наиболее подробно описан $f w 2.2$ - первый регуляторный локус, который был картирован международной группой исследователей под руководством генетика S.D. Tanksley (An. Frary с соавт., 2000). Этот локус контролирует мелкоплодность и проявляет полудоминироваие по отношению к полурецессивному аллелю крупноплодности $F W 2.2$. В серии экспериментов с использованием трансгенных линий установлено, что локус $f w 2.2$ содержится внутри космиды cos50, анализ сиквенса которой выявил две открытых рамки считывания. Одна из них содержала единичное рекомбинационное событие, которое ограничивало локус $f w 2.2$ с правого конца, - ХO33. Так как местом локализации одной или нескольких генетических мутаций, вызывающих изменение размера плода, может быть только участок слева от ХОЗ3, кДНК44 не может вовлекаться в процессы увеличения размера плода, и ген $O R F X$, или upstream регион, фенотипически проявляется в виде стандартного мелкоплодного образца $(f w 2.2)$. Затем было установлено, что $f w 2.2$ действует как негативный регулятор клеточного деления на самых ранних стадиях развития плода - после опыления. Таким образом, $f w 2.2$ - один из ряда регуляторных локусов количественных признаков (quantitative trait loci, QTL), действующий в процессе увеличения размера плода, таких как achaete-scute, scabrous, Delta у культур, имеющих плоды, teosinte-branched 1 (tb1) у кукурузы и Нох-гены у животных (цит. по В. Cong с соавт., 2006). Локус FW2.2, вероятно, выступает в роли позитивного регулятора клеточного деления и вовлечен во взаимодействие с цитоплазматическими мембранами при участии регуляторной ( $\beta)$-субъединицы СКII-киназы, которая, как известно, формирует часть клеточного цикла, связанного с путями сигналинга у клеток дрожжей и животных (В. Cong с соавт., 2006).

Ключевые слова: Solanum lycopersicum L., томат, селекция, наследуемость, крупноплодность, средняя масса плода, низкорослость, регуляторные QTL, развитие плода.

Основной современный тренд в овощеводстве защищенного грунта многоярусные узкостеллажные гидропонные и аэропонные установки (вертикальное овощеводство), позволяющие получать урожайность зелени в 530 раз выше, чем на обычном поле $(1,2)$. Для заполнения емкого (1) 
и быстрорастущего (2) рынка вертикального овощеводства основными культурами (томат, огурец, перец сладкий) потребовался новый взгляд на селекцию как технологический процесс. Зная особенности фенотипического проявления генов, контролирующих ключевой признак (карликовость), мы разработали целевую технологию отбора форм овощных культур для вертикального овощеводства $(3,4)$, с помощью которой получили первые в мире мелкоплодные сорта томата для многоярусной узкостеллажной гидропоники - Наташа и Тимоша (5). Генетический анализ (6) и целевая гибридизация с использованием в скрещиваниях крупноплодных материнских форм привели к увеличению средней массы плода у поколения F3 практически в 2 раза (7). Но укрупнение плода у томата - сложный количественный признак. Следовательно, для эффективного создания крупноплодных сортов необходимо знание не только генетических детерминант этого признака, но и механизмов, модулирующих их фенотипическое проявление. В своем обзоре мы сконцентрировали внимание на анализе данных о генах, участвующих в контроле массы плода у томата, и возможностях регулировать их экспрессию, которые, по нашему мнению, представляют первоочередной интерес для селекции.

Цель обзора - обобщение сведений о генетических детерминантах массы плода у томата и их связи с процессами органогенеза, а также с гормональной и метаболической регуляцией развития плода.

Плод томата (Solanum lycopersicum Mill.) - многогнездная ягода, которая широко используется как модель сочного плода как в агрономических, так и в фундаментальных исследованиях (8-10). Предковая форма домашнего томата имела плоды менее 1 см в диаметре с массой несколько граммов. Изменение размера плода связано с доместикацией. Мы зафиксировали массу плода томата 780 г (2018 год) (2), но есть сведения, что у современных томатов она может достигать 1000 г при диаметре более 15 см (11).

Локусы, контролирующие размер плода. У томата размер плода контролируется полигенно. Большинство из 37 локусов, вовлеченных в эволюцию и доместикацию томата от мелкоплодных форм к более крупноплодным, генетически картированы $(12,13)$.

Первым картированным локусом, контролирующим размер плода у томата, был $f w 2.2$. Обусловливая мелкоплодность, этот локус ведет себя, как полудоминантный по отношению к полурецессивному аллелю крупноплодности $F W 2.2$ (11). Все исследованные дикие виды $S$. lycopersicum несут аллели мелкоплодности $f w 2.2$, в то время как современные сорта - аллели крупноплодности $F W 2.2$. Международная группа исследователей клонировала и секвенировала сегмент размером 19 т.п.н., содержащий локус $f w 2.2$, а также идентифицировала гены, ответственные за эффект этого локуса (11). Теми же авторами была создана генетическая карта высокого разрешения для локуса $f w 2.2$ на основе четырех уникальных транскриптов, выявленных у 3472 растений поколения F2 от скрещивания двух почти изогенных линий, различающихся по аллелям $f w 2.2$ (рис.) (11). Четыре кДНК, соответствующие этим транскриптам, использовали для скрининга библиотеки космид, несущих фрагменты геномной ДНК S. pennellii. В результате идентифицировали четыре позитивные неперекрывающиеся космиды (cos50, $\cos 62, \cos 69$ и $\cos 84)$, каждая из которых соответствовала одному из уникальных транскриптов. Использовав трансгенные линии, присутствие $f w 2.2$ детектировали в $\cos 50$. Секвенирование этой космиды выявило две открытых рамки считывания (см. рис.): первая соответствовала кДНК44 (одна из четырех уникальных кДНК), по которой идентифицировали cos50, для второй (663н.) соответствующих 
транскриптов исходно в библиотеке не обнаружили. Инсерция содержала высокоповторяющийся участок размером 1,4 т.п.н., обогащенный АТ (80 \%) (см. рис., В). Предшествующее картирование $f w 2.2$ выявило единичное рекомбинационное событие [ХО33], которое ограничивало с правого конца локус $f w 2.2$. Сравнение геномного ДНК-сиквенса у этого рекомбинантного растения с таковым у двух родительских линий показало локализацию ХО 33 между 43-м и 80-м нуклеотидами с 5'-конца открытой рамки считывания X (ORFX) (см. рис., А). Так как генетическая мутация(и), вызывающая(ие) изменение размера плода, может быть только слева от ХO33, кДНК44 не может вовлекаться в процессинг увеличения размера плода, и ORFX или upstream регион фенотипически проявляется в виде стандартного мелкоплодного образца ( $f w 2.2)$.

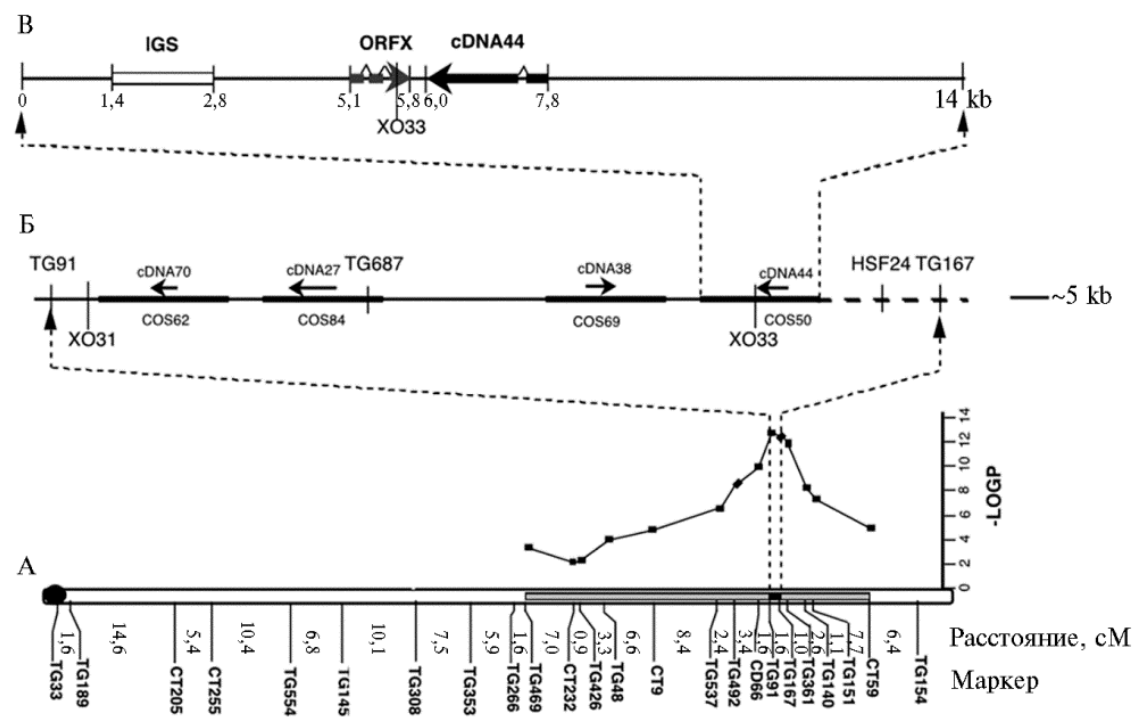

Картирование высокого разрешения локуса $f w 2.2$ (11).

А. Расположение $f w 2.2$ на второй хромосоме в скрещиваниях между Solanum lycopersicum и изогенной линией, содержащей небольшую интрогрессию из S. pennellii.

Б. Контиг из региона-кандидата $f w 2.2$, ограниченный рекомбинациями при XO31 и ХO33. Стрелками отмечены четыре оригинальных кандидата кДНК (cDNA70, cDNA27, cDNA38 и cDNA44), жирными горизонтальными линиями - четыре космиды $(\cos 62, \cos 84, \cos 69$, $\cos 50)$, изолированные с этими кДНК как пробы.

В. Сиквенс космиды $\cos 50$, включающий рекомбинацию ХО33.

Эти же авторы (11) обнаружили открытую рамку считывания (ORFX) в органах цветка (лепестках, карпелах, чашелистиках и тычинках) перед цветением. Поскольку ORFX транскрибируется на уровне, слишком низком для обнаружения с помощью стандартных протоколов Nothernгибридизации, авторы использовали метод полимеразной цепной реакции с обратной транскрипцией (RT-PCR) и установили, что самый высокий уровень экспрессии ORFX наблюдается в карпелах (плодолистиках). Изучение относительных уровней экспрессии ORFX-транскриптов в карпелах у разных изогенных линий выявило существенно более высокий уровень экспрессии ORFX-транскриптов в карпелах у мелкоплодных изогенных линий по сравнению с крупноплодными. Исследование ORFX-транскрипции в карпелах перед цветением подтверждает, что $f w 2.2$ усиливает свое действие на ранних стадиях развития растения. Для того чтобы проверить эту гипотезу, авторы сравнили массы цветочных органов у мелкоплодных и крупноплодных изогенных линий (11). Карпелы (которые впоследствии развиваются в 
плоды), пестики и чашелистики перед цветением у крупноплодных изогенных линий были всегда тяжелее, чем у мелкоплодных. Размеры клеток перед цветением оказались сходны у обоих типов изогенных линий, значит, карпелы крупноплодных генотипов содержат больше клеток. Анализ аллельных различий $f w 2.2$ и $F W 2.2$ сравнением фрагмента 830 п.н., содержащего ORFX, у $S$. pennellii и $S$. lycopersicum привел к выводу, что в случае fw2.2 фенотип вызван одним или несколькими upstream изменениями в промоторном регионе ORFX. При этом редукция деления клеток в карпелах мелкоплодных изогенных линий коррелирует с общим ростом числа ORFX-транскриптов, подтверждая, что ORFX может быть негативным регулятором клеточного деления (11). Убедительные доказательства этому получили в более поздних работах, выполненных в той же лаборатории (14). Было установлено, что $f w 2.2$ действует как негативный регулятор клеточного деления на самых ранних стадиях развития плода - после опыления. Таким образом, $f w 2.2-$ один из регуляторных локусов количественных признаков (quantitate train loci, QTL) увеличения размера плода, подобных, например, локусам achaetescute, scabrous, Delta у культур, имеющих плоды, teosinte-branched 1 (tb 1) у кукурузы и Нох генам животных, у которых морфологические изменения отражают скорее вариации в регуляции генов, чем модификацию функций белков (цит. по 14). Что же касается локуса $F W 2.2$, то он, по всей вероятности, выполняет роль позитивного регулятора (прямого или косвенного) деления клеток. Между локусом $F W 2.2$ и мембранами цитоплазмы осуществляется взаимодействие при посредстве регуляторной $\beta$-субъединицы CKIIкиназы. CKII-киназы хорошо изучены у дрожжей и животных, у которых они участвуют в клеточном цикле и связаны с путями сигналинга. Таким образом, FW2.2, хотя и является специфичным растительным белком (11) и регулирует деление клеток в специализированном органе (плоде), он, по-видимому, участвует в клеточном контроле сигнальной трансдукции (14).

Локус $F W 2.2$ относится к мультигенному семейству (включает у томата 17 гомологов), которое обычно обозначают как $F W 2.2$-like или $F W L$ гены. Белки FW2.2 и FWL содержат неохарактеризованный Placenta-specific 8 (PLAC8) мотив, который впервые был идентифицирован у белков, выделенных из плаценты млекопитающих (15). PLAC8 мотив содержит два консервативных домена, обогащенных цистеином, отделяющих вариабельный регион, который предшествует трансмембранным сегментам. У томата оригинальные белки FW2.2 обладают двумя трансмембранными доменами, которые фиксируют белок на плазмалемме (14). Из более ранних сообщений вытекает, что обогащенные цистеином домены могут вовлекаться в трансмембранный перенос тяжелых металлов, например кадмия и цинка. Впервые это установили у белков устойчивых к кадмию растений Arabidopsis. Такой тип белков может мультимеризоваться в гомопентамер для формирования трансмембранной поры, в связи с чем приобретается возможность транспорта катионов металлов (16).

$F W 3.2$ - второй крупный QTL, определяющий размер/массу плода, который был картирован у томата и клонирован (17). Гены, составляющие этот локус, кодируют энзим Р450 из подсемейства СYР78А5, ранее идентифицированного как KLUH (18). Эффект SIKLUH состоит в увеличении объема плода через увеличение числа клеток в тканях перикарпия и перегородки. Подавление функции SIKLUH с помощью стратегии РНК-интерференции приводило к снижению размера плода и семян (17).

$F W 11.3$ - еще один важный QTL, отвечающий за массу плода у томата (19). Четкое картирование выявило перекрывание $F W 11.3$ с локусом 
fasciated (fas), который определяет форму плода и расположен на 11-й хромосоме, но при этом $F W 11.3$ и fas не являются аллелями (20). Аллель крупноплодности $F W 11.3$ (в отличие от $F W 2.2$ и $f a s)$ частично доминантный (19).

Сложное семейство локусов, контролирующих размер/массу плода у томата, часто перекрывается с локусами, ответственными за форму плода, что, по мнению некоторых авторов, стало результатом доместикации и тесно связано с регуляторными функциями этих локусов (21). Поэтому мы также рассмотрим QTLs, контролирующие форму плода у S. lycopersicum. В отличие от предковой круглой формы, современные томаты представлены круглыми, плоскими, эллипсоидными, грушевидными, сердцевидными, овальными и вытянутыми формами. Но все многообразие этих форм контролируют только четыре мутантных гена - OVATE, SUN, FASCIATED (FAS), LOCULE NUMDER (LC) (22).

OVATE - это первый контролирующий форму плода ген, который был идентифицирован с помощью позиционного клонирования (23). Он является платформой для семейства белков ovate, функции которых до конца не выяснены $(23,24)$. Действие мутации ovate выражается в появлении плодов удлиненной, грушевидной и эллипсоидной формы в зависимости от генотипического фона растения, несущего мутацию ovate (25). Указанное разнообразие подтверждает, что $O V A T E$ не является единственным геном, ответственным за наблюдаемый фенотип, а взаимодействует с другими генами по типу эпистаза (23). Предполагается, что мутация OVATE связана с утраченной функцией негативного регулятора роста растений, роль которого еще предстоит выяснить. Например, у Arabidopsis белки семейства OVATE действуют как траскрипциональные репрессоры экспрессии AtGA20ox1 - ключевого фактора биосинтеза гибберелловой кислоты, что уменьшает растяжение клетки и, следовательно, может отражаться на размере плода $(24,26,27)$.

С геном $S U N$ связана удлиненная форма плода. Ретротранспозон, помещающий этот ген под контроль промотора гена дефензина DEFL1, обеспечивает дупликацию этого гена, что приводит к его высокой экспрессии в плоде $(28,29)$. Сверхэкспрессия гена $S U N$ увеличивает число клеток в направлении удлинения плода, что в итоге формирует фенотип с вытянутым плодом (30).

Число локул у плода (ген $L O C U L E N U M D E R, L C)$ определяется числом карпел внутри цветка. У диких видов томата встречаются плоды с 2-4 локулами, в то время как современные сорта и гибриды могут иметь более 15 локул в плоде. В результате изменяется не только форма, но и размер/масса плода, иногда более чем на $50 \%$ (9).

QTL FASCIATED (FAS) был идентифицирован как локус, регулирующий размер плода за счет увеличения числа локул (с 2 до 7 и более), в то время как мутация $l c$ имеет более слабый эффект $(31,32)$. FAS кодирует YАВВY-подобный транскрипционный фактор (33), а $L C$ расположен в некодирующем регионе между двумя потенциальными генами-кандидатами - WUSCHEL, который является членом семейства генов транскрипционного фактора $W U S$ ( $W O X)$, специфичного для растений, и геном, кодирующим белок, несущий WD40-повтор (34). Функции большинства $W O X$ генов известны очень давно (35). Более специфичные гены WUS вовлечены в сохранение толщины стебля и размера меристемы, и, следовательно, WUSCHEL может влиять на число локул. FAS и LC способны взаимодействовать эпистатически и давать плоды с очень большим числом локул (36). Оба этих локуса контролируют размер флоральной меристемы, следовательно, возможно развитие большого числа карпел (локул), приводящее к 
появлению плодов огромного размера $(33,34)$.

Функциональный анализ с использованием TOMATO AGAMOUSLIKE1 (TAGL1) - ортолога дуплицированного SHATTERPROOF (SHP) $M A D S$ box гена Arabidopsis thaliana показал вовлечение этого транскрипционного фактора в регуляцию развития плода (37). Растения томата, у которых экспрессия TAGL1 подавлялась, продуцировали мелкие плоды с тонким перикарпием, состоящим из нескольких слоев клеток, при этом также изменялась пигментация плодов при созревании, что указывало на участие TAGL1 в регуляции этих процессов.

Органогенез: развитие плода томата. Плоды обычно развиваются из предшествующих органов, например из карпел (плодолистиков) внутри цветка. У томата карпелы формируются за 17-20 циклов клеточного деления, которое происходит перед цветением внутри слоя L3 флоральной меристемы, которая не вовлекается в расширение клетки $(38,39)$. Очевидно, что число клеток, сформировавшихся до цветения, критично для окончательного размера плода, и такая положительная корреляция наблюдается часто (9). От начала цветения до двойного оплодотворения, происходящего в семяпочках $(8,40)$, процесс морфогенеза и роста карпел и семяпочек требует синтеза и действия ауксинов, цитокининов и гиббереллинов, осуществляемых комплексно (в пространстве и времени). Для того чтобы защитить яйцеклетку и на определенное время сохранить ее в состоянии покоя, абсцизовая кислота и этилен внутри завязи сдерживают рост яйцеклетки в течение короткого периода до цветения - до тех пор, пока она не созреет (41). Только после успешного опыления и оплодотворения семяпочек процесс завершается с помощью триггеров завязывания плода синтезируемых завязью ауксинов и гиббереллинов (42).

Увеличение размера плода у томата - первая и самая длительная фаза его развития, она занимает 5-8 нед в зависимости от генотипа. Рост обусловлен первым периодом интенсивной митотической активности - в соответствии с пространственной и временно́й организацией процесса клеточного деления. Активное деление клеток внутри перикарпия обычно ограничено начальным периодом 1-2 нед после завязывания плода. Замечательно то, что деление клеток начинается внутри дискретных клеточных слоев по определенному сценарию: два субэпидермальных слоя перикарпия подвергаются нескольким циклам периклинальных делений, приводя, таким образом, к повышению числа периклинальных клеточных слоев, в то время как два эпидермальных клеточных слоя в ответ подвергаются антиклинальным делениям, что приводит к увеличению объема плода (43). Эти различные типы деления клеток регулируются дифференцированно, потому что деление клеток способствует формированию клеточных слоев, возникающих только в течение 5-8 сут после цветения, в то время как менее ориентированное клеточное деление происходит в течение 10-18 сут после цветения (43). Делением клеток в растущих плодах охвачено примерно 80-97 \% заново формирующихся клеток, возникающих после цветения и успешного опыления.

Вторая фаза роста связана с расширением клеток, происходящим самостоятельно, но сопутствующим делению клеток (8). Фактически расширение клеток начинается через несколько суток после завязывания плодов (43) и сохраняется весь период роста плода. В конце фазы расширения клеток индивидуальные клетки в мясистой части плода (ткани мезокарпия) увеличиваются в объеме более чем в 30000 раз, что приводит к увеличению диаметра клетки более чем на 0,5 мм (43). Увеличение объемов клеток происходит в основном за счет существенного увеличения объема вакуолярного 
компартмента и вакуолярного индекса клетки. Эта ожидаемая гипертрофия клеток обусловлена ростом количества ядерной ДНК благодаря эндополиплоидизации. Эндополиплоидия представляет собой появление разных уровней плоидности внутри организма. У растений она происходит в результате эндоредупликации, которая наблюдается, по разным оценкам, у 90 \% покрытосеменных растений $(44,45)$. Эндоредупликация приводит к возникновению хромосом с $2 n$ хроматидами или происходит без каких-либо изменений в числе хромосом. Далее возникают гипертрофированные ядра - из сукцессивных циклов ДНК-репликации без разделения на сестринские хроматиды, что приводит в итоге к образованию политенных хромосом (46). Физиологическая значимость эндоредупликации все еще остается предметом дискуссий. Однако часто отмечают, что размер клетки и плоидность высоко и позитивно коррелируют между собой у многих видов растений, в разных органах и у разных типов клеток (47). На каждом этапе органогенеза действуют определенные группы регуляторных полигенных локусов, так или иначе связанных с изменением размера плода томата (13). В развитие яйцеклетки вовлечены локусы TAGL1, FAS, LC, SlWUS, SIIMA. В период цветения в ауксиновом сигналинге задействованы гены SIPIN4, SITIR1, SlARF7, SlARF8, SIIAA9, в гиббереллиновом - SlGA20ox1 и SIDELLA1. На этапе роста плода в делении клеток участвуют SlCDKA1, SlCDCB1, SlCDKB2 (контроль клеточного цикла), FW2.2, SlKLUH/FW3.2, FW11.3, OVATE, SUN, SIIMA (контроль деления клеток) и SIPIN4 (ауксиновый сигналинг). В период увеличения объема плода (расширение клеток) активны SlCCS52A, SlWEE1, SIKRP1 (контроль клеточного цикла), HXK1, SuSY, LIN5, TIV1, $m M D H, c p F B P$ (первичный метаболизм), SIIAA17 (ауксиновый сигналинг), $S P A$ (регуляция первичного метаболизма), NOTABILIS/NCED1, FLACCA (биосинтез абсцизовой кислоты) и Gal-LDH, GME (биосинтез аскорбатов) (13).

Гормональная регуляция формирования и развития плода. После успешного опыления цветка и оплодотворения яйцеклетки, завязывания плодов и семян наступает стадия образование завязи с последующим развитием плодов и семян, происходящим синхронно в соответствии с точным, генетически контролируемым процессом при посредничестве фитогормонов (8). Ауксин и гибберелловая кислота - по-видимому, предшествуют фитогормонам, необходимым для завязывания плодов в ответ на опыление, так как экзогенное применение этих фитогормонов приводит к образованию завязи и развитию партенокарпии (48). Роль цитокинина, этилена и абсцизовой кислоты была продемонстрирована позже, но не так хорошо задокументирована (49). Ранние процессы развития плода, управляемые распределенными в тканях и клетках ауксинами, инициируют пути сигнальной трансдукции. Показано, что PIN-формируемый ауксином выброс транспортных белков необходим для завязывания и раннего развития плода у томата (50). Молчание гена SIPIN4, который сначала экспрессируется в цветочных почках и молодых развивающихся плодах, приводит к партенокарпии плодов маленького размера, что указывает на преждевременное развитие этих плодов (51). В сигнальный путь ауксина вовлечен ауксиновый рецептор - белок-ингибитор транспортного ответа (TIR1). B присутствии ауксина TIR1 вовлекает в процесс репрессоры транскрипции ауксин-индолил-3-масляной кислоты (Аux/IAA) и индуцирует их деградацию с помощью 26S протеасомы. Деградация репрессора белков Aux/IAA приводит к появлению Аuх/ІАА-связанных факторов ауксинового ответа (ARF). Ошибочная экспрессия гена ауксинового рецептора TIR1 у томата, как и ошибочная экспрессия специфических членов этого генного семейства $(A u x / I A A$ и $A R F)$ нарушает процессы цветения-образования завязи, в 
результате не происходит нормального опыления и оплодотворения, что повышает число партенокарпических плодов на растении томата $(48,52,53)$. У томата завязывание плодов частично обусловлено гибберелловыми кислотами в комплексе гормонального обмена информацией с ауксином (54). Ауксин, синтезируемый в яйцеклетке и апикальных побегах, предотвращает появление неоплодотворенных яйцеклеток за счет снижения транскрипции генов, кодирующих биосинтез энзимов гибберелловых кислот, в частности GA-20-оксидаз (55). Таким образом, фитогормоны выполняют роль посредников в сигнальных путях транспортных белков и белков - факторов транскрипции в процессе завязывания и развития плода у томата, они вовлечены в регуляцию размера плода с участием ряда генов, организованных в сложные системы.

Метаболический контроль развития плода. Ранние стадии развития плода критичны для формирования хозяйственно ценных характеристик, например органолептического состава, который в конечном счете определяет качество плодов. Вода, органические кислоты (в первую очередь цитрат и малат) и минералы накапливаются внутри вакуолей расширяющихся клеток (38), в то время как крахмал быстро конвертируется в простые сахара (56). Мягкость плода, его окраска и вкус формируются в процессе созревания $(57,58)$. Развитие и масса плода тесно связаны с содержанием входящих в его состав первичных и вторичных метаболитов $(59,60)$. Следовательно, модификация экспрессии генов, связанных с метаболизмом, может влиять на органолептические свойства и массу плода томата. В то же время развитие плода как сочного органа в большей степени зависит от накопления фотоассимилятов: изменение ассимиляционного накопления существенно влияет на развитие и размер плода через модуляцию числа и размера клеток $(61,62)$. Когда растение томата выдерживают в темноте, рост плода существенно замедляется в результате сильного подавления генов клеточного цикла внутри тканей плода (63). Наоборот, повышение фотоассимиляционной способности плода при снижении числа плодов на куст приводило к увеличению скорости образования цветков и роста плодов. Об этом свидетельствует большее число клеток внутри карпел вследствие повышения митотической активности (64). Таким образом, модификация метаболизма углеводов и фотоассимилятов, частично управляемая ключевыми энзимами, вовлеченными в первичный метаболизм углеводов и процесс фотосинтеза, может влиять на рост плода.

QTL Lin5 был идентифицирован как основной QTL, контролирующий массу плода и содержание сахара (65). Было установлено, что связанные с ним гены кодируют инвертазу клеточной стенки (66). Когда Lin5 отключали с помощью сайленсинга, урожай плодов, размер плода и семени и число семян существенно снижались (67). В трансгенных растениях изменения затрагивали метаболизм сахаров, поэтому содержание сахарозы возрастало, а содержание глюкозы и фруктозы на стадии полной спелости снижалось. Сайленсинг гена вакуолярной инвертазы (TIRI) у томата давал в целом сходные результаты. Образование мелких плодов было обусловлено высокой скоростью накопления сахарозы и снижением количества гексозы на завершающей стадии развития плода (68). Интересно, что изменения в концентрации осмотически активных растворимых сахаров возникали в течение фазы расширения клетки и влияли на размер плода. Это подтверждает идею о том, что концентрация растворимых сахаров связана с увеличением объема воды, который выступает важной детерминантой увеличения размера плода.

При поиске геномных регионов QTL, связанных с признаками уро- 
жайности, L. Bermudez c соавт. (69) идентифицировали 9 генов-кандидатов, расположенных на 4-й хромосоме. В частности, был выявлен ген, кодирующий протеин, подобный шаперону DnaJ, и сделано предположение о его связи с первичным метаболизмом у томата при развитии плода. Функциональный анализ этого гена, впоследствии названного SPA (sugar partitioningaffecting - влияющий на разделение сахаров) in planta методом сайленсинга показал, что масса зрелого плода, число плодов на растении, и уборочный индекс существенно выше у трансгенных растений, чем у растений дикого типа (70). Подробный анализ метаболической и ферментативной активности показал, что при сайленсинге в фотосинтетических органах растений накапливались промежуточные метаболиты (фосфаты сахаров), тогда как активность фосфоглюкомутазы, сахарокиназ и инвертаз снижалась. SPA белок томатов взаимодействует с тилакоидными мембранами хлоропластов, играет важную роль в метаболизме, влияет на перераспределение углеводов и в итоге изменяет уборочный индекс (70).

В современных исследованиях QTLs, определяющих размер и форму плода у томата, делается акцент на комплексный характер действия аллелей. Так, Y.-Н. Chu с соавт. (71) вполне определенно утверждают, что число локул и размер плода у томата контролируются природными аллелями $l c$ и fas. LC кодирует томатный ортолог WUSCHEL (WUS), в то время как $F A S$ кодирует томатный ортолог CLAVATA3 (CLV3). Ведущая роль связки WUS-CLV3 в организации меристемы была продемонстрирована у нескольких видов растений. Авторы этой работы показали, что мутация обоих локусов у томата приводит к повышению уровня экспрессии $S l W U S$ в цветочных почках через 2-3 сут после инициации. Единичные и двойные мутантные аллели $l c$ и fas сохраняют высокий уровень экспрессии SIWUS при развитии карпел в цветочной почке (71). Другие авторы, комбинируя технику картирования сиквенсов и метод редактирования геномов CRISPR-Cas9, выявили локус фактора транскрипции AP2/ERF, регулирующий активность цветочной меристемы, который они назвали EXCESSIVE NUMBER OF FLORAL ORGANS ( $E N O)$ (72). Мутация гена $E N O$ приводит к повышению количества мультилокулярных плодов на растении в результате разрастания цветочной меристемы. Генетический анализ выявил синергетический эффект мутаций LOCULE NUMDER (локус SIWUS) и FASCIATED (локус SICLV3) - двух центральных мутаций в эволюции размера плода томата при доместикации (72). В результате обширного исследования, выполненного традиционными (Тоmato Analyser) и современными (EcoTILLING) методами, группа индийских ученых установила, что популяция одного сорта томата, обладающего низким уровнем полиморфизма, выявленного с помощью EcoTILLING, тем не менее, демонстрировала широкое фенотипическое разнообразие. Авторы объясняют полученные результаты тем, что фенотипическое разнообразие представляет собой результат взаимодействия между геномом, транскриптомом, протеомом и метаболомом (73). В контексте исследуемой темы это означает, что не столько единичные гены контролируют размер и массу плода у томата, сколько регуляторные QTLs, о чем было упомянуто выше $(71,72)$. Особый интерес представляют работы, посвященные действию регуляторных QTLs, вовлеченных в метаболические пути ауксина и гиббереллина, на завязывание и регулирование размера плода у томата $(74,75)$, но мы считаем, что этой тематике следует посвятить отдельный обзор.

Итак, анализ литературных источников, описывающих генетические детерминанты размера плода у томата, привел нас к следующим заключениям. Контроль размера плода у Solanum lycopersicum L. осуществляется 
группой локусов, регулирующих процессы деления и расширения клеток на четырех разных этапах развития плода - от развития яйцеклетки и формирования завязи после оплодотворения до клеточного деления и расширения клеток, формирующих зрелый плод. К настоящему времени известно 37 таких локусов. Эти локусы могут перекрываться с локусами, контролирующими форму плода у $S$. lycopersicum, и вовлекаться в сигнальные пути фитогормонов и процессы первичного и вторичного метаболизма. Генетические детерминанты процессов деления и расширения клеток вовлечены в сигнальные пути ауксина и гиббереллина, а потому использование перечисленных фитогормонов для изменения размера плода вполне вероятно. Развитие и масса плода у томата тесно связаны с содержанием первичных и вторичных метаболитов. Модификация экспрессии генов, связанных с первичным и вторичным метаболизмом, может приводить к изменению органолептического состава и массы плода томата, регулируя уборочный индекс и влияя на распределение углеводов, а, следовательно, и на биохимический состав плода томата.

ФГБНУ Федеральный научный иентр овощеводства,

Поступила в редакцию 143080 Россия, Московская обл., Одинцовский р-н, пос. ВНИИССОК, ул. Селекционная, 14, 3 декабря 2019 года

e-mail: balashova56@mail.ru $\bowtie$, sirota@vniissok.ru, techh620@yandex.ru

Sel'skokhozyaistvennaya biologiya [Agricultural Biology], 2020, V. 55, № 5, pp. 876-889

\title{
LARGE FRUIT OF TOMATO Solanum lycopersicum L.: GENETIC DETERMINANTS, ORGANOGENESIS AND FRUIT DEVELOPMENT (review)
}

\author{
I.T. Balashova ${ }^{\bowtie}$, S.M. Sirota, E.V. Pinchiuk
}

Federal Research Center for Vegetable Growing, 14, ul. Selektsionnaya, pos. VNIISSOK, Odintsovskii Region, Moscow Province, 143080 Russia, e-mail: balashova56@mail.ru ( $₫$ corresponding author), sirota@vniissok.ru, techh620@yandex.ru ORCID:

Balashova I.T. orcid.org/0000-0001-7986-2241 Sirota S.M. orcid.org/0000-0001-5792-8502

The authors declare no conflict of interests Received December 3, 2019

Pinchiuk E.V. orcid.org/0000-0003-0824-8864

doi: 10.15389/agrobiology.2020.5.876eng

\section{Abstract}

Large fruit in Solanum lycopersicum L. is the result of domestication. We were interested in the appearance of large fruits in tomato in connection with the practice task to get new tomato forms with large fruits for multi-tiered hydroponic and aeroponic installations for vertical fruit production in greenhouses. Using the technology of target tomato breeding we obtained the first special dwarf tomato varieties Natasha and Timosha with small fruits for multi-tiered hydroponic installations. Obtaining of large fruit in tomato is connected with genetic and epigenetic control of the trait (An. Frary et al., 2000; B. Cong et al., 2006; Z. Huang et al., 2011; S. Wang, et al., 2011; A.J. Monforte et al., 2014; L. Azzi et al., 2015). The goal of this review is to summarize data on genetic determinants the trait of "size/weight of the fruit", analysis processes of organogenesis, hormone and metabolic regulation of fruit development. Analysis of papers dedicated to fruit weight increasing during domestication shows the availability of 37 loci involved in regulation of cell division and enlargement at four different stages of fruit development, starting from the phases of ovary development and fruit set to the phases of cell development and enlargement of cells which form the mature fruit. Some of these loci are connected with processes of hormonal plant development at the phase of anthesis, fertilization, formation of fruits and seeds, and so, they are involved in auxin (SIPIN4, SITIR1, SIARF7, SIARF8, SIIAA9) and gibberellin (SlGA20ox1, SIDELLA1) signaling pathways. Others control cell enlargement during fruit development and maturing, and so, they are involved in regulation of primary (HXK1, SuSY, LIN5, TIV1, $m M D H, c p F B P, S P A)$ and secondary (NOTABILIS/NCED1, FLACCA, Gal-LDH, GME) metabolism. Individual group of loci controls cell cycle at the period of ovary development (TAGL1, FAS, LC, SlWUS, SlIMA) and fruit growth (SlCDKA1, SlCDCB1, SlCDKB2 and SlCCS52A, SlWEE1, SlKRP1) (L. Azzi et al., 2015). The $f w 2.2$ is the first locus which has been described in detail (An. Frary et al., 
2000). Locus $f w 2.2$ controls the small fruit size in S. lycopersicum and is semidominant to allele $F W 2.2$ of large fruit size. With transgenic lines, it had been established, that locus $f w 2.2$ is carried by $\cos 50$. Sequence analysis of the cos50 had identified two open reading frames. One of them contain a single recombinant event, which delimited "the rightmost" end of the $f w 2.2$ (XO33). Because genetic mutation(s) causing change in fruit size must be to the left of XO33, cDNA44 cannot be involved and open reading frame is the likely cause of the small-fruit phenotype. Next studies indicated that fw2.2 acts as a negative regulator of cell division during the very early stages of fruit development following pollination. Thus, $f w 2.2$ is one of regulatory QTLs, such as achaete-scute, scabrous and Delta QTLs in fruit flies, teosinte-branched 1(tb1) in maize and Hox genes in animals (cited by B. Cong et al., 2006). Possible, locus FW2.2 is positive regulator of cell division, which is involved in interaction with cytoplasmic membranes mediated by the regulatory (beta)-subunits of CKII kinase, that is well known in yeast and animals where it forms part of cell cycle related with signaling pathway (B. Cong et al., 2006).

Keywords: Solanum lycopersicum L., tomato, breeding, heritability, large fruits, average fruit weight, dwarfism, regulatory QTLs, fruit development.

\section{REFERENCES}

1. Global Industry Report, 2014-2025, April, 2017, Report ID: IVR 1-68038-797-1.

2. Balashova I.T., Sirota S.M., Pinchuk E.V. Vertical vegetable growing: creating tomato varieties for multi-tiered hydroponic installations. International Conference on Sustainable Development of Cross-Border Regions. IOP Conference Series: Earth and Environmental Science. Barnaul, 2019, 395 (012079): 1-8 (doi: 10.1088/1755-1315/395/1/012079).

3. Sirota S.M., Balashova I.T., Kozar' E.G., Pinchuk E.V. Ovoshchi Rossii, 2016, 4(33): 3-9 (in Russ.).

4. Balashova I.T., Sirota S.M., Kozar E.G., Pivovarov V.F. Target tomato breeding for special hydroponic technology. Abstracts of 20th EUCARPIA Congress. Switzerland, Zurich, 2016: 343.

5. Balashova I.T., Sirota S.M., Kozar' E.G., Pinchuk E.V. Vestnik Orlovskogo gosudarstvennogo agrarnogo universiteta, 2017, 3(66): 71-74 (in Russ.).

6. Pivovarov V.F., Balashova I.T., Sirota S.M., Kozar' E.G., Pinchuk E.V. Improvement of sporophyte selection for the purpose of acceleration of tomato breeding for narrow shelf hydroponics technology. Sel'skokhozyaistvennaya biologiya [Agricultural Biology], 2013, 1: 95-101 (doi: 10.15389/agrobiology.2013.1.95eng).

7. Pivovarov V.F., Balashova I.T., Sirota S.M., Kozar' E.G., Pinchuk E.V. Analysis of hybridization effect by the appearance of target tomato traits in $\mathrm{F}_{2}, \mathrm{~F}_{3}$ progenies in breeding for multi circle hydroponics. Sel'skokhozyaistvennaya biologiya [Agricultural Biology], 2017, 52(5): 1049-1055 (doi: 10.15389/agrobiology.2017.5.1049eng).

8. Gillaspy G., Ben-David H., Gruissem W. Fruits: a developmental perspective. The Plant Cell, 1993, 5(10): 1439-1451 (doi: 10.1105/tpc.5.10.1439).

9. Tanksley S.D. The genetic, developmental and molecular bases of fruit size and shape variation in tomato. The Plant Cell Online, 2004, 16(suppl_1): 181-189 (doi: 10.1105/tpc.018119).

10. Klee H.J., Giovannoni J.J. Genetics and control of tomato fruit ripening and quality attributes. Annual Review of Genetics, 2011, 45(1): 41-59 (doi: 10.1146/annurev-genet-110410-132507.

11. Frary An., Nesbitt T.C., Frary Am., Grandillo S., Van der Knaap E., Cong B., Liu J.P., Meller J., Elber R., Alpert K.B., Tanksley S.D. fw2.2: A quantitative trait locus key to the evolution of tomato fruit size. Science, New Series, 2000, 289(5476): 85-88 (doi: 10.1126/science.289.5476.85).

12. Grandillo S., Ku H.M., Tanksley S.D. Identifying loci responsible for natural variation in fruit size and shape in tomato. Theoretical and Applied Genetics, 1999, 99(6): 978-987 (doi: $10.1007 / \mathrm{s} 001220051405)$.

13. Azzi L., Deluche C., Gévudant F., Frangne N., Delmas F., Hernould M., Chevalier C. Fruit growth-related genes in tomato. Journal of Experimental Botany, 2015, 66(4): 1-12 (doi: $10.1093 / \mathrm{jxb} / \mathrm{eru} 527)$.

14. Cong B., Tanksley S.D. FW2.2 and cell cycle control in the developing tomato fruit: a possible example of gene co-option in the evolution of a novel organ. Plant Molecular Biology, 2006, 62(6): 867-880 (doi: 10.1007/s11103-006-9062-6).

15. Guo M., Rupe M.A., Dieter J.A., Zou J., Spielbauer D., Duncan K.E., Howard R.J., Hou Z., Simmons S.R. Cell Number Regulator 1 affects plant and organ size in maize: implications for crop yield enhancement and heterosis. The Plant Cell, 2010, 22(4): 1057-1073 (doi: 10.1105/tpc.109.073676).

16. Song W.Y., Choi K.S., Kim D.Y. Geisler M., Park J., Vincenzetti V., Schellenberg M., Kim S.H., Lim Y.P., Noh E.W., Lee Y., Martinoia E. Arabidopsis PCR2 is a zinc exporter involved in both zinc extrusion and long-distance zinc transport. The Plant Cell, 2010, 22(7): 2237-2252 (doi: $10.1105 /$ tpc.109.070185). 
17. Chakrabarti M., Zhang N., Sauvage C., Mucios S., Blanca J., Cacizares J., Diez M.J., Schneider R., Mazourek M., McClead J., Causse M., Van der Knaap E., A cytochrome P450 regulates a domestication trait in cultivated tomato. Proceedings of the National Academy of Sciences, 2013, 110(42): 17125-17130 (doi: 10.1073/pnas.1307313110).

18. Anastasiou E., Kenz S., Gerstung M., MacLean D., Timmer J., Fleck C., Lenhard M. Control of plant organ size by KLUH/CYP78A5-depended intercellular signaling. Developmental Cell, 2007, 13(6): 843-856 (doi: 10.1016/j.devcel.2007.10.001).

19. van der Knaap E., Tanksley S.D. The marking of a bell-pepper shaped tomato fruit: identification of loci controlling fruit morphology in Yellow Stuffer tomato. Theoretical and Applied Genetics, 2003, 107(1): 139-147 (doi: 10.1007/s00122-003-1224-1).

20. Huang Z., van der Knaap E. Tomato fruit weight 11.3 maps close to fascinated on the bottom on chromosome 11. Theoretical and Applied Genetics, 2011, 123(3): 465-474 (doi: 10.1007/s00122011-1599-3).

21. Monforte A.J., Diaz A., Caco-Delgrado A., van der Knapp E. The genetic basis of fruit morphology in the horticultural crops: lessons from tomato to melon. Journal of Experimental Botany, 2014, 65(16): 4525-4537 (doi: 10.1093/jxb/eru017).

22. Rodriguez G.R., Mucos S., Anderson C., Sim S.C., Michel A., Causse M., McSpadden Gardener B.B., Francis D., van der Knapp E. Distribution of $S A N$, OVATE, LC and FAS in the tomato germplasm and the relationship to fruit shape diversity. Plant Physiology, 2011, 156(1): 275-285 (doi: 10.1104/pp.110.167577).

23. Liu J., Van Eck J., Cong B., Tanksley S.D. A new class of regulatory genes underlying the cause of pear-shaped tomato fruit. Proceedings of the National Academy of Sciences, 2002, 99(20): 1330213306 (doi: 10.1073/pnas.162485999).

24. Wang S., Chang Y., Guo J., Zeng Q., Ellis B.E., Chen J.G. Arabidopsis Ovate family proteins, a novel transcriptional repressor family, control multiply aspects of plant growth and development. PLoS ONE, 2011, 6(8): 23896 (doi: 10.1371/journal.pone.0023896).

25. Gonsalo M.J., van der Knapp E. A comparative analysis into the genetic basis of morphology in tomato varieties exhibiting elongated fruit shape. Theoretical and Applied Genetics, 2008, 116(5): 647-656 (doi: 10.1007/s00122-007-0698-7).

26. Hackbusch J., Richter K., Mbller J., Salamini F., Uhrig J.F. A central role of Arabidopsis thaliana ovate family proteins in networking and subcellular localization of a 3-aa loop extension homeodomain proteins. Proceedings of the National Academy of Sciences, 2005, 102(13): 4908-4912 (doi: 10.1073/pnas.0501181102).

27. Wang S., Chang Y., Guo J., Chen J.-G. Arabidopsis Ovate Family Protein 1 is a transcriptional repressor, that suppresses cell elongation. The Plant Journal, 2007, 50(5): 858-872 (doi: 10.1111/j.1365-313X.2007.03096.x).

28. Xiao H., Jiang N., Schaffner E., Stockinger E.J., van der Knapp E. A retrotransposon-mediated gene duplication underlines morphological variation of tomato fruit. Science, 2008, 319(5869): 1527-1530 (doi: 10.1126/science.1153040).

29. Jiang N., Gao D., Xiao H., van der Knapp E. Genome organization of the tomato sun locus and characterization of unusual retrotransposon reader. The Plant Journal, 2009, 60(1): 181-193 (doi: 10.1111/j.1365-313X.2009.03946.x).

30. Wu S., Xiao H., Cabrera A., Meulia T., van der Knapp E. $S U N$ regulate vegetative and reproductive organ shape by changing cell division patterns. Plant Physiology, 2011, 157(3): 1175-1186 (doi: 10.1104/pp.111.181065).

31. Lippman Z., Tanksley S.D. Dissecting the genetic pathway to extreme fruit size in tomato using a cross between the small-fruited wild species Lycopersicum pimpinellifolium and L. esculentum var. Giant Heirloom. Genetics, 2001, 158(1): 413-422.

32. Barrero L.S., Cong B., Wu F., Tanksley S.D. Developmental characterization of the fascinated locus and mapping of the Arabidopsis candidate genes involved in the control of floral meristem size and carpel number in tomato. Genome, 2006, 49(8): 991-1006 (doi: 10.1139/g.06-059).

33. Cong B., Barrero L.S., Tanksley S.D. Regulatory change in YABBY-like transcriptional factor led to evolution of extreme fruit size during tomato domestication. Nature Genetics, 2008, 40(6): 800-804 (doi: 10.1038/ng.144).

34. Mucos S., Ranc N., Botton E. Bйrard A., Rolland S., Duffé P., Carretero Y., Le Paslier M.-C., Delalande C., Bouzayen M., Brunel D., Causse M. Increase in tomato locule number is controlled by two single-nucleotide polymorphisms located near WUSCHEL. Plant Physiology, 2011, 156(4): 2244-2254 (doi: 10.1104/pp.111.173997).

35. van der Graaff E., Laux T., Rensing S.A. The WUS homeobox-cotaining (WOX) protein family. Genome Biology, 2009, 10(12): 248 (doi: 10.1186/gb-2009-10-12-248).

36. Barrero L.S., Tanksley S.D. Evaluating the genetic basis of multiple-locule fruit in a broad cross section of tomato cultivars. Theoretical and Applied Genetics, 2004, 109(3): 669-679 (doi: 10.1007/s00122-004-1676-y).

37. Vrebalov J., Pan I.L., Arroyo A.J.M., McQuinn R., Chung M.Y., Poole M., Rose J., Seymour G., Grandillo S., Giovannoni J., Irish V.F. Fleshy fruit expansion and ripening are regulated by the tomato SHATTERPROOF gene TAGL1. The Plant Cell, 2009, 21(10): 3041-3062 (doi: 
10.1105/tpc.109.066936).

38. Coombe B. The development of fleshy fruits. Annual review of plant physiology. Waite Agricultural Research Institute, The University of Adelaide, Glen Osmond, South Australia, 1976: 507-528.

39. Ho L.C. Fruit growth and sink strength. In: Fruit and seed production: aspect of development, environmental physiology and ecology. C. Marshall, J. Grace (eds.). University Press, Cambridge, 1992: 101-124.

40. Brukhin V., Hernould M., Gonzalez N., Chevaleir C., Mouras A. Flower development schedule in tomato, Lycopersicum esculentum cv. Sweet Cherry. Sexual Pant Reproduction, 2003, 15: 311 320 (doi: 10.1007/s00497-003-0167-7).

41. Vriezen W.H., Feron R., Maretto F., Keijman J., Mariani C. Changes in tomato ovary transcriptome demonstrate complex hormonal regulation of fruit set. New Phytologist, 2008, 177(1): 60-76 (doi: 10.1111/j.1469-8137.2007.02254.x).

42. Ruan Y.-L., Patrick J.W., Bouzayen M., Osorio S., Fernie A.R. Molecular regulation of seed and fruit set. Trends in Plant Science, 2012, 17(11): 656-665 (doi: 10.1016/j.tplants.2012.06.005).

43. Cheniclet C., Rong W.Y., Causse M., Frangne N., Bolling L., Carde J.-P., Ranaudin J.-P. Cell expansion and endoreduplication show a large genetic variability in pericarp and contribute strongly tomato fruit growth. Plant Physiology, 2005, 139(4): 1984-1994 (doi: 10.1104/pp.105.068767).

44. Nagl W. DNA endoreduplication and polyteny understood as evolutionary strategies. Nature, 1976, 261(5561): 614-615 (doi: 10.1038/261614a0).

45. D'Amato F. Role of polyploidy in reproductive organs and tissues. In: Embryology of angiosperms. Springer, Berlin, Heidelberg, 1984: 519-566 (doi: 10.1007/978-3-642-69302-1_11).

46. Bourdon M., Pirello J., Cheniclet C., Coriton O., Bourge M., Brown S., Monse A., Peypelut M., Rouyère V., Renaudin J.-P., Chevalier C., Frangne N. Evidence for karyoplasmic homeostasis during endoreduplication and a ploidy-dependent increase in gene transcription during tomato fruit growth. Development, 2012, 139(20): 3817-3826 (doi: 10.1242/dev.084053).

47. Chevalier C., Nafati M., Mathieu-Rivet E., Bourdon M., Frangne N., Cheniclet C., Ranaudin J.P., Gévaudant F., Hernould M. Elucidation the functional role of endoreduplication in tomato fruit development. Annals of Botany, 2011, 107(7): 1159-1169 (doi: 10.1093/aob/mcq257).

48. De Jong M., Wolters-Arts M., Feron R., Mariani C., Vriezen W.H. The Solanum lycopersicum auxin response factor 7 (SlARF7) regulates auxin signaling during tomato fruit set and development. The Plant Journal, 2008, 57(1): 160-170 (doi: 10.1111/j.1365-313X.2008.03671.x).

49. Kumar R., Khurana A., Sharma A. Role of plant hormones and their interplay in development and ripening of fleshy fruits. Journal of Experimental Botany, 2014, 65(16): 4561-4575 (doi: 10.1093/jxb/eru277).

50. Pattison R.J., Catalá C. Evaluating of auxin distribution in tomato (Solanum lycopersicum) through an analysis of the PIN and $A U X / L A X$ gene families. The Plant Journal, 2012, 70(4): 585-598 (doi: 10.1111/j.1365-313x.2011.04895.x).

51. Mounet F., Moing A., Kowalczyk M., Rohrmann. J., Petit J., Garcia V., Maucourt M., Yano K., Deborde C., Aoki K., Bergès H., Granell A., Fernie A.R., Bellini C., Rothan C., LemaireChamley M. Down-regulation of a single auxin efflux transport protein in tomato induces precocious fruit development. Journal of Experimental Botany, 2012, 63(13): 4901-4917 (doi: $10.1093 / \mathrm{jxb} / \mathrm{ers} 167)$.

52. Wang H., Jones B., Li Z., Frasse P., Delalande C., Regard F., Chaabouni S., Latchй A., Pech J.C., Bouzayen M. The tomato Aux/IAA transcription factor IAA9 is involved in fruit development and leaf morphogenesis. The Plant Cell, 2005, 17(10): 2676-2692 (doi: 10.1105/tpc.105.033415).

53. Ren Z., Li Z., Miao Q., Yang Y., Deng W., Hao Y. The auxin receptor homolog in Solanum lycopersicum stimulates tomato fruit set and leaf morphogenesis. Journal of Experimental Botany, 2011, 62(8): 2815-2826 (doi: 10.1093/jxb/erq455).

54. Serrani J.C., Ruiz-Rivero O., Fos M., García - Martínez J.L. Auxin-induced fruit set in tomato is mediated in part by gibberellins. The Plant Journal, 2008, 56(6): 922-934 (doi: 10.1111/j.1365313X.2008.03654.x).

55. Serrani J.C., Sanjuan R., Ruiz-Rivero O., Fos M., Garsia-Martinez J.L. Gibberellin regulation of fruit set and growth in tomato. Plant Physiology, 2007, 145(1): 246-257 (doi: 10.1104/pp.107.098335).

56. Wang F., Sanz A., Brenner M.L., Smith A. Sucrose synthase, starch accumulation, and tomato fruit sink strength. Plant Physiology, 1993, 101(1): 321-327 (doi: 10.1104/pp.101.1.321).

57. Giovannoni J.J. Genetic regulation of fruit development and ripening. The Plant Cell Online, 2004, 16(suppl 1): S170-S180 (doi: 10.1105/tpc.019158).

58. Gapper N.E., MacQuinn R.P., Giovannoni J.J. Molecular and genetic regulation of fruit ripening. Plant Molecular Biology, 2013, 82(6): 575-591 (doi: 10.1007/s11103-013-0050-3).

59. Carrari F., Fernie A.R. Metabolic regulation underlying tomato fruit development. Journal of Experimental Botany, 2006, 57(9): 1883-1897 (doi: 10.1093/jxb/erj020).

60. Tohge T., Alseekh S., Fernie A.R. On the regulation and function of secondary metabolism during fruit development and ripening. Journal of Experimental Botany, 2014, 65(16): 4599-4611 (doi: 
10.1093/jxb/ert443).

61. Bohner J., Bangerth F. Cell number, cell size and hormone levels in semi-isogenic mutants of Lycopersicum pimpinellifolium differing in fruit size. Physiologia Plantarum, 2006, 72(2): 316-320 (doi: 10.1111/j.1399-3054.1988.tb05839.x).

62. Bertin N., Cuatier H., Roche C. Number of cells in tomato fruit depending on fruit position and source-sink balance during plant development. Plant Growth Regulation, 2002, 36(2): 105-112 (doi: 10.1023/A:1015075821976).

63. Baldet P., Devaux C., Chevalier C., Brouquisse R., Just D., Raymond P. Contrasted responses to carbohydrate limitation in tomato fruit at two stages of development. Plant, Cell and Environment, 2002, 25(12): 1639-1649 (doi: 10.1046/j.1365-3040.2002.00941.x).

64. Baldet P., Hernould M., Laporte F., Mounet F., Just D., Mouras A., Chevalier C., Rothan C. The expression of cell proliferation-related genes in early developing flower is affected by fruit load reduction in tomato plants. Journal of Experimental Botany, 2006, 57(4): 961-970 (doi: 10.1093/jxb/erj082).

65. Fridman E., Pleban T., Zamir D. A recombination hotspot delimits a wild-species quantitative trait locus for tomato sugar content to $484 \mathrm{bp}$ within an invertase gene. Proceeding of the National Academy of Sciences, 2000, 97(9): 4718-4723 (doi: 10.1073/pnas.97.9.4718).

66. Fridman E., Carrari F., Liu Y.S., Fernie A.R., Zamir D. Zooming in on a quantitative trait for tomato yield using interspecific introgressions. Science, 2004, 305(5691): 1786-1789 (doi: 10.1126/science.1101666).

67. Zanor M.I., Osorio S., Nunes-Nesi A., Carrari F., Lohse M., Usadel B., Kühn C., Bleiss W., Giavalisco P., Willmitzer L., Sulpice R., Zhou Y.-H., Fernie A.R. RNA interference of LIN5 in tomato confirms its role in controlling Brix content, uncovers the influence of sugar on the levels of fruit hormones and demonstrate the importance of sucrose cleavage for normal fruit development and fertility. Plant Physiology, 2009, 150(3): 1204-1218 (doi: 10.1104/pp.109.136598).

68. Gilbert L., Alhagdow M., Nunes-Nesi A., Quemener B., Guillon F., Bouchet B., Faurobert M., Gouble B., Page D., Garcia V., Petit J., Stevens R., Causse M., Fernie A.R., Lahaye M., Rothan C., Baldet P. GDP-d-mannose 3,5- epimerase (GME) plays a key role in the intersection of ascorbate and non-cellulosic cell-wall biosynthesis in tomato. The Plant Journal, 2009, 60(3): 499-508 (doi: 10.1111/j.1365-313x.2009.03972.x).

69. Bermúdez L., Urias U., Mistein D., Kanenetzky L., Asis R., Fernie A.R., Van Sluys M.A., Carrari F., Rossi M. A candidate gene survey of quantitative trait loci, affecting chemical composition in tomato fruit. Journal of Experimental Botany, 2008, 59(10): 2875-2890 (doi: 10.1093/jxb/ern146).

70. Bermúdez L., de Godoy F., Baldet P., Demarco D., Osorio S., Quadrana L., Almeida J., Asis R., Gibon Y., Fernie A.R., Rossi M., Carrari F. Silencing of the tomato Sugar Partitioning Affecting protein (SPA), modifies sink strength through a shift a leaf sugar metabolism. The Plant Journal, 2014, 77(5): 676-687 (doi: 10.1111/tpj.12418).

71. Chu Yi-H., Jang J.-Ch., Huang Z., Van der Knapp E. Tomato locule number and fruit size controlled by natural alleles of $l c$ and fas. Plant Direct, 2019, 3(7): e00142 (doi: 10.1002/pld3.142).

72. Yuste-Lisbona F.J., Fernȧndez-Lozano A., Pineda B., Bretones S., Ortiz-Atienza A., GarciaSogo B., Müller N.A., Angosto T., Capel J., Moreno V., Jiménez-Gómez J.M., Lozano R. ENO regulates tomato fruit size through the floral meristem development network. Proceeding of the National Academy of Sciences, 2020, 117(14): 8187-8195 (doi: 10.1073/pnas.1973688117).

73. Mohan V., Gupta S., Thomas S., Mickey H., Charakana Ch., Chauhan V.S., Sharma K., Kumar R., Tyagi K., Sarma S., Gupta S.K., Kilambi H.V., Nongmaithem S., Kumari A., Gupta P., Sreelakshmi Ye., Sharma R. Tomato fruits show phenomic diversity but fruit developmental genes show low genomic diversity. PLoS ONE, 2016, 11(4): e0152907 (doi: 10.1371/journal.pone.0152907).

74. Quinet M., Angosto T., Yuste-Lisbona F.J., Blanchard-Gros R., Bigot S., Martinez J.-P., Lutts S. Tomato fruit development and metabolism. Frontiers in Plant Science, 2019, 10: 1554 (doi: 10.3389/fpls.2019.01554).

75. Liu S., Zhang Y., Feng Q., Qin L., Pan Ch., Lamin-Samu A.T., Gang L. Tomato AUXIN RESPONSE FACTOR 5 regulates fruit set and development via the mediation of auxin and gibberellin signaling. Science Report, 2018, 8: 2971 (doi: 10.1038/s41598-018-21315-y). 